\title{
Prevalence of Renal Impairment in a US Commercially Insured Rheumatoid Arthritis Population: A Retrospective Analysis
}

\author{
Jon T. Giles · Lee S. Simon · Janet Pope · Jim S. Paik • Michael Grabner (D) • \\ Amanda Quebe · Carol L. Kannowski (D) C Claudia A. Salinas • \\ Jeffrey R. Curtis
}

Received: April 22, 2021 / Accepted: July 5, 2021 / Published online: July 28, 2021

(C) The Author(s) 2021

\section{ABSTRACT}

Introduction: Global prevalence estimates for chronic kidney disease (CKD) in rheumatoid arthritis (RA) vary. This study assessed realworld prevalence estimates of renal impairment, based on estimated glomerular filtration rate (eGFR), among commercially insured patients with RA in the United States (US).

Methods: In this retrospective cohort study, we used administrative claims data from the HealthCore Integrated Research Database $\left(\right.$ HIRD $\left.^{\circledR}\right)$ between January 2013 and December

\section{J. T. Giles ( $₫)$}

Division of Rheumatology, College of Physicians and Surgeons, Columbia University, $630 \mathrm{~W}$ 168th St P\&S Building, Suite 3-450, New York, NY 10032, USA

e-mail: jtg2122@cumc.columbia.edu

L. S. Simon

SDG LLC, Cambridge, MA, USA

J. Pope

Division of Rheumatology, University of Western

Ontario, London, ON, Canada

J. S. Paik - A. Quebe · C. L. Kannowski · C. A. Salinas Eli Lilly and Company, Indianapolis, IN, USA

M. Grabner

HealthCore, Inc, Wilmington, DE, USA

J. R. Curtis

Division of Clinical Immunology and

Rheumatology, University of Alabama at

Birmingham, Birmingham, AL, USA
2018. Adult patients with $\geq 2$ claims for RA and $\geq 2$ serum creatinine (SCr) measurements $\geq 90$ days apart on or after the index date were included. eGFR was calculated per the Modification of Diet in Renal Disease equation. Prevalence of eGFR-based renal impairment was estimated for the overall RA population and for two subgroups: patients on advanced therapies (biologic disease-modifying antirheumatic drugs/tofacitinib) and patients stratified based on health plan types.

Results: Among 128,062 patients with $\geq 2$ RA claims, 42,173 had qualifying SCr measurements, 16,197 were on advanced RA therapies, and 4911 had Medicare Advantage or Supplemental plus Part D coverage. For the overall population and the subgroup on advanced therapies, mild renal impairment was observed in $52 \%$ and $51 \%$, moderate renal impairment in $9 \%$ and $7 \%$, and severe renal impairment in $0.5 \%$ and $0.3 \%$ of patients, respectively. Moderate and severe renal impairment was more prevalent in the Medicare Advantage/ Supplemental plus Part D population compared to the commercial coverage population.

Conclusions: Approximately $7-10 \%$ of commercially insured adult patients in the US with RA had moderate or severe renal impairment. Assessment of renal function is an important consideration for safe treatment. 
Keywords: Estimated glomerular filtration rate; MDRD; Real-world evidence; Renal impairment; Rheumatoid arthritis

\section{Summary slide}

Why carry out this study?

Renal impairment in rheumatoid arthritis (RA) may influence treatment choice and increase mortality.

Reports citing prevalence of renal impairment among patients with RA in the United States (US) vary widely due to different assessment techniques, geographic restrictions, and/or small sample size.

This study assessed prevalence of estimated glomerular filtration rate-based renal impairment among adult patients with RA in the US. The aim was to provide a more contemporary view using a large, nationally representative US cohort, treated in the community.

What was learned from the study?

Prevalence of moderate or severe renal impairment was estimated to be $\sim 10 \%$ among commercially insured patients with RA, and $\sim 7 \%$ in a subgroup of patients on advanced therapies; prevalence was higher among managed Medicare compared to commercial coverage patients.

Assessment of renal function is an important consideration for safe treatment for RA.

The outcomes of the study underpin the importance of renal function assessment among patients with RA for appropriate selection and dosing of medications.

\section{INTRODUCTION}

Renal dysfunction in rheumatoid arthritis (RA) may influence treatment and increase mortality [1]. It may result from comorbidities, chronic inflammation, aging, or medication effects $[1,2]$. Regular assessment of renal function is important to inform dosage adjustment of medications, such as methotrexate, nonsteroidal anti-inflammatory drugs (NSAIDs), and Janus kinase inhibitors (JAKi) $[3,4]$. These commonly used medications in RA have the potential to affect renal function and can result in toxicity even in mild renal dysfunction [3].

Chronic kidney disease (CKD) is characterized by decreases in glomerular filtration rate (GFR) or presence of $\geq 1$ markers of kidney damage for $>3$ months [5]. The prevalence of CKD in RA has been reported in frequencies ranging from 5 to $50 \%[3,6-8]$. Methods for quantifying renal impairment differed in these studies, and there were potential limitations such as geographic restriction, and/or small sample sizes $[1,7,9,10]$.

This study aimed to assess the prevalence of estimated GFR (eGFR)-based renal impairment among adult patients with RA in the United States (US). We have conducted this study to provide a more contemporary view of renal impairment in RA using a large, nationally representative US cohort, treated in the community.

\section{METHODS}

In this retrospective cohort study, we used claims data from the HealthCore Integrated Research Database $\left(\right.$ HIRD $\left.^{\circledR}\right)$ between January 1, 2013 and December 31, 2018. The HIRD ${ }^{\circledR}$ encompasses a diverse spectrum of longitudinal medical and pharmacy claims data, and laboratory data from health plan members across the US.

\section{Patient Population}

Patients were required to have $\geq 2$ claims $\geq 7$ days apart with diagnosis codes for 
RA $(714.0 \times, 714.1 \times, 714.2 \times \quad$ [International Classification of Diseases, Ninth Revision, Clinical Modification/ ICD-9-CM] and M05.\%, M06.0\%, M06.8\% [International Classification of Diseases, Tenth Revision, Clinical Modification/ICD-10-CM]) and $\geq 2$ serum creatinine (SCr) measurements $\geq 90$ days apart. For patients with $>2$ measurements, the first two measurements were used. The index was the date of the earliest RA claim. Characteristics of patients with and without SCr measurements are shown in Table 1 . Patients aged $\geq 18$ years on index date with $\geq 1$ day of enrollment during the study period were identified. No minimum enrollment before or after the index date was required. Patients with a claim during the study period for juvenile idiopathic arthritis, ankylosing spondylitis, psoriatic arthritis, or lupus were excluded.

Researchers' access to claims data was limited to data stripped of identifiers to ensure confidentiality. HealthCore maintains data use agreements with the covered entities in compliance with the Health Insurance Portability and Accountability Act. Permission was obtained from HealthCore to access the database. An Institutional Review Board did not review the study since only this limited data set was accessed.

Table 1 Characteristics of patients with and without $\geq 2$ serum creatinine lab results

\begin{tabular}{lll}
\hline Characteristics & $\begin{array}{l}\text { All RA patients, } \\
\boldsymbol{n}=\mathbf{1 2 8 , 0 6 2}\end{array}$ & $\begin{array}{l}\text { RA patients with } \geq \mathbf{2} \text { SCr lab results, } \\
\boldsymbol{n}=\mathbf{4 2 , 1 7 3}\end{array}$ \\
\hline Age, mean (SD) & $58.0(14.1)$ & $55.5(12.3)$ \\
Females & 74.8 & 75.9 \\
Plan type & & \\
Commercial coverage & 81.3 & 88.4 \\
Medicare Advantage & 9.3 & 7.6 \\
Medicare Supplemental/Part D & 9.4 & 4.0 \\
Region & & \\
Northeast & 15.0 & 15.9 \\
Midwest & 26.3 & 13.9 \\
South & 33.2 & 40.1 \\
West & 21.2 & 25.5 \\
Comorbidities & & \\
$\geq 1$ medical claim for hypertension & 42.4 & 40.1 \\
$\geq 1$ pharmacy claim for & 42.5 & 42.2 \\
antihypertensives & & 3.2 \\
$\geq 1$ medical claim for heart failure & 4.8 & 15.8 \\
$\geq 1$ medical claim for diabetes & 15.8 & 10.7 \\
$\geq 1$ pharmacy claim for antidiabetics & 10.2 &
\end{tabular}

All values are \% unless otherwise indicated

$n$ number of patients in each group, $R A$ rheumatoid arthritis, $S C r$ serum creatinine, $S D$ standard deviation

${ }^{a}$ Within a window of -90 days to +90 days around the index date 


\section{Assessment of Renal Function}

eGFR was estimated using the Modification of Diet in Renal Disease (MDRD) equation, where eGFR is expressed in $\mathrm{ml} / \mathrm{min} / 1.73 \mathrm{~m}^{2}$, serum creatinine in $\mathrm{mg} / \mathrm{dl}$, and age in years [11]. This method, proposed by the Food and Drug Administration, is employed in package inserts for recently approved medications for RA [12].

$$
\begin{aligned}
\mathrm{eGFR}= & 175 \times \text { standardized } \mathrm{SCr}^{(-1.154)} \\
& \times \operatorname{age}^{(-0.203)} \times 0.742(\text { if female }) \\
& \times 1.212(\text { if black }) .
\end{aligned}
$$

Race information was unavailable, and individuals were designated non-black for calculation.

\section{Prevalence Assessment}

In this descriptive analysis, prevalence of eGFRbased renal impairment by severity (classifications based on Kidney Disease Improving Global Outcomes guidelines 2012, see Table 2) was calculated [13]. Grades 4 and 5 were combined given the low frequency (i.e., $<1 \%$ in aggregate). Patients falling into $>1$ severity category were classified into the less severe category. Prevalence was calculated overall and for commercial and Medicare Advantage/Supplemental/Part D (Medicare) populations; for a subset of patients with $\geq 1$ claim for advanced therapies (abatacept, adalimumab, anakinra, certolizumab pegol, etanercept, golimumab, infliximab, rituximab, sarilumab, tocilizumab, tofacitinib citrate) on or after the index date; and on an annual basis among patients who had $\geq 2$ SCr measurements in the year of interest.

\section{RESULTS}

A sample of $128,062 \mathrm{RA}$ patients was identified from the HIRD ${ }^{\circledR}$. Among them, 42,173 had $\geq 2$ SCr measurements and 16,197 had $\geq 1$ claim for advanced therapies. Mean (standard deviation) age was 56 (12) years and $76 \%$ were female (Table 3). Patients were stratified by health plan type (commercial plan: $n=37,262$; Medicare: $n=4911$ ). Assessed comorbidities (hypertension, heart failure, and diabetes) were more frequent in the Medicare population (Table 3).

\section{Prevalence of Renal Impairment by Severity}

Renal impairment was observed in $62 \%$ of patients in the overall population, and $58 \%$ of patients treated with advanced therapies; the majority had mild impairment, 7-9\% had moderate impairment, and $<1 \%$ had severe impairment (Table 4). Prevalence estimates were consistent over time (Fig. 1).

\section{Prevalence of Renal Impairment by Health Plan}

The proportion of patients with moderate renal impairment was higher in the Medicare group

Table 2 Classification of renal impairment based on estimated glomerular filtration rates

\begin{tabular}{lll}
\hline & Grade $^{\mathbf{a}}$ & eGFR $\left(\mathbf{m l} / \mathbf{m i n} / \mathbf{1 . 7 3} \mathbf{~ m}^{\mathbf{2}}\right)$ \\
\hline Normal GFR & G1 & $\geq 90$ \\
Mild decrease in GFR & G2 & $60-89$ \\
Moderate decrease in GFR & G3 & $30-59$ \\
Severe decrease in GFR & G4 & $15-29$ \\
End-stage renal disease & G5 & $<15$ \\
\hline
\end{tabular}

a Thresholds for the severity group definitions are based on existing guidance. Thomas et al. 2008 [13] eGFR estimated glomerular filtration rate 
Table 3 Patient demographic and clinical characteristics

\begin{tabular}{|c|c|c|c|c|}
\hline Variable & $\begin{array}{l}\text { All patients }{ }^{\mathrm{a}} \\
(n=42,173)\end{array}$ & $\begin{array}{l}\text { Patients treated with } \\
\text { advanced therapies } \\
(n=16,197)\end{array}$ & $\begin{array}{l}\text { Patients with Medicare } \\
\text { Advantage or Supplemental plus } \\
\text { Part D coverage }(n=4911)\end{array}$ & $\begin{array}{l}\text { Patients with } \\
\text { commercial insurance } \\
\text { coverage }(n=37,262)\end{array}$ \\
\hline $\begin{array}{l}\text { Age in years, mean } \\
\text { (SD) }\end{array}$ & $55.5(12.3)$ & $53.1(11.3)$ & $72.1(8.9)$ & $53.4(10.9)$ \\
\hline Female & 75.9 & 77.1 & 74.9 & 76.0 \\
\hline $\begin{array}{l}\text { Medicare } \\
\text { Advantage or } \\
\text { Supplemental } \\
\text { plus Part D }\end{array}$ & 11.6 & 6.7 & - & - \\
\hline \multicolumn{5}{|l|}{ Region of residence } \\
\hline Northeast & 15.9 & 12.8 & 33.3 & 13.6 \\
\hline Midwest & 13.9 & 12.9 & 22.0 & 12.8 \\
\hline South & 40.1 & 43.1 & 25.1 & 42.1 \\
\hline West & 25.5 & 26.4 & 19.6 & 26.2 \\
\hline \multicolumn{5}{|l|}{ Comorbidities } \\
\hline Hypertension $^{c}$ & 40.1 & 33.1 & 68.4 & 36.3 \\
\hline Heart failure $^{c}$ & 3.2 & 1.8 & 10.6 & 2.2 \\
\hline Diabetes $^{c}$ & 15.8 & 12.2 & 27.0 & 14.3 \\
\hline
\end{tabular}

All values are $\%$ unless otherwise indicated

$R A$ rheumatoid arthritis, $S D$ standard deviation

${ }^{a}$ With at least two SCr laboratory test results available

b Advanced therapies included abatacept, adalimumab, anakinra, certolizumab pegol, etanercept, golimumab, infliximab, rituximab, sarilumab, tocilizumab, and tofacitinib citrate

${ }^{c}$ Based on presence of $\geq 1$ medical claim with ICD-9/10-CM codes for the disease of interest, in a window \pm 90 days around the index date (first diagnosis of RA)

Table 4 Prevalence of renal impairment by severity category

\begin{tabular}{lll}
\hline $\begin{array}{l}\text { Severity of renal impairment } \\
\text { confidence interval) }\end{array}$ & $\begin{array}{l}\text { All patients } \\
(\boldsymbol{n}=\mathbf{4 2 , 1 7 3})\end{array}$ & $\begin{array}{l}\text { Patients treated with advanced therapies }^{\mathbf{c}} \\
(\boldsymbol{n}=\mathbf{1 6}, \mathbf{1 9 7})\end{array}$ \\
\hline Mild (grade 2) & $52.1(51.6,52.6)$ & $50.9(50.1,51.6)$ \\
Moderate (grade 3) & $9.3(9.0,9.6)$ & $7.0(6.6,7.4)$ \\
Severe (grade 4-5) & $0.5(0.4,0.6)$ & $0.3(0.2,0.4)$ \\
Overall (any impairment level) & $61.9(61.4,62.3)$ & $58.2(57.4,58.9)$ \\
\hline
\end{tabular}

${ }^{a}$ Mild: eGFR $=60-90 \mathrm{ml} / \mathrm{min} / 1.73 \mathrm{~m}^{2} ;$ moderate: eGFR $=30-59 \mathrm{ml} / \mathrm{min} / 1.73 \mathrm{~m}^{2} ;$ severe: eGFR $=<30 \mathrm{ml} / \mathrm{min} /$ $1.73 \mathrm{~m}^{2}$

${ }^{\mathrm{b}}$ With at least two SCr laboratory test results available

c Advanced therapies included abatacept, adalimumab, anakinra, certolizumab pegol, etanercept, golimumab, infliximab, rituximab, sarilumab, tocilizumab, and tofacitinib citrate

$e G F R$ estimated glomerular filtration rate, $n$ number of patients in each group, $S C r$ serum creatinine 
Table 5 Prevalence of renal impairment by health plan type

\begin{tabular}{|c|c|c|c|c|}
\hline \multirow[t]{2}{*}{$\begin{array}{l}\text { Severity of renal } \\
\text { impairment }^{a}(\%)\end{array}$} & \multicolumn{2}{|c|}{ Commercial plan coverage } & \multicolumn{2}{|c|}{$\begin{array}{l}\text { Medicare advantage or supplemental plus } \\
\text { part } D \text { coverage }\end{array}$} \\
\hline & $\begin{array}{l}\text { All patients } \\
(n=37,262)\end{array}$ & $\begin{array}{l}\text { Patients treated with advanced } \\
\text { therapies }{ }^{c}(n=15,107)\end{array}$ & $\begin{array}{l}\text { All patients } \\
(n=4911)\end{array}$ & $\begin{array}{l}\text { Patients treated with } \\
\text { advanced therapies } \\
(n=1090)\end{array}$ \\
\hline Mild (grade 2) & 51.9 & 50.6 & 53.6 & 55.0 \\
\hline Moderate (grade 3) & 7.2 & 6.0 & 25.5 & 20.6 \\
\hline Severe (grade 4-5) & 0.4 & 0.2 & 1.3 & 0.9 \\
\hline $\begin{array}{l}\text { Overall (any } \\
\text { impairment level) }\end{array}$ & 59.4 & 56.8 & 80.5 & 76.5 \\
\hline \multicolumn{5}{|c|}{$\begin{array}{l}\text { a Mild: eGFR }=60-90 \mathrm{ml} / \mathrm{min} / 1.73 \mathrm{~m}^{2} ; \text { moderate: eGFR }=30-59 \mathrm{ml} / \mathrm{min} / 1.73 \mathrm{~m}^{2} \text {; and severe: eGFR }=<30 \mathrm{ml} / \\
\min / 1.73 \mathrm{~m}^{2} \\
\mathrm{~b} \text { With at least two SCr laboratory test results available } \\
{ }^{c} \text { Advanced therapies included abatacept, adalimumab, anakinra, certolizumab pegol, etanercept, golimumab, infliximab } \\
\text { rituximab, sarilumab, tocilizumab, and tofacitinib citrate } \\
\text { eGFR estimated glomerular filtration rate, } n \text { number of patients in each group, } S C r \text { serum creatinine }\end{array}$} \\
\hline
\end{tabular}

with RA and $\sim 7 \%$ in a subgroup of patients on advanced therapies. The prevalence was higher among Medicare compared to commercial coverage patients.

Renal impairment in RA is relevant to inform drug treatment (e.g., avoidance of NSAIDs) and dose selection (e.g., methotrexate), as patients can accumulate multiple treatments undergoing renal elimination. The MDRD equation for eGFR incorporates age, sex, and SCr and is a validated tool to assess renal function $[3,12]$.

Earlier studies estimating eGFR by MDRD were limited to single centers, small populations, and did not include US patients with RA. Prevalence rates of renal impairment $\left(\mathrm{eGFR}<60 \mathrm{ml} / \mathrm{min} / 1.73 \mathrm{~m}^{2}\right)$ ranged from 8 to $19 \%$ across these studies [3, 6-8].

Our study included a large cohort of US patients with available SCr laboratory measurements. This claims-based study also has limitations. Some patients with severe renal impairment are not commercially insured and would not appear in the HIRD ${ }^{\circledR}$. While MDRD is the method presently employed in US package inserts and associated dosage adjustments, newer methods (e.g., Chronic Kidney Disease
Epidemiology Collaboration [CKD-EPI]) may be employed in practice [14]. Some literature suggests that MDRD may estimate a slightly higher proportion with CKD compared to CKD-EPI [15]. SCr measurements were available for $46 \%$ of patients with RA in the database, potentially limiting generalizability. Because race is not captured, patients were designated non-black for purposes of eGFR calculation. As patients were required to have two RA claims, there is the possibility for underestimation of cases in the event of death or transition from commercial coverage before the second claim. RA diagnosis claims were used for identification irrespective of associated provider specialty and claims for renal impairment were not examined; different approaches may help quantify uncertainty around the CKD prevalence estimates. The association between renal impairment and factors such as patient demographics (e.g., gender and geographical area of residence), comorbidities, or concomitant medications (e.g., methotrexate, NSAIDs, etc.) or for specific medication classes (e.g., JAKi) was not assessed in this project; however, it should be considered in future research. 


\section{CONCLUSIONS}

In summary, moderate or severe renal impairment was present in $\sim 10 \%$ of insured patients with RA in the US. These findings support assessment of renal function in patients with RA to enable appropriate selection and dosing of medications.

\section{ACKNOWLEDGEMENTS}

Funding. Study funding and the journal's Rapid Service Fee was provided to HealthCore, Inc. by Eli Lilly and Company.

Authorship. All named authors meet the International Committee of Medical Journal Editors (ICMJE) criteria for authorship for this article, take responsibility for the integrity of the work as a whole, and have given their approval for this version to be published.

Author Contributions. JTG, LSS, JP, JSP, MG, AQ, CLK, CAS, and JRC have made substantial contributions to conception, design, analysis, and interpretation of data. All authors were involved in revising the manuscript critically for important intellectual content.

Medical Writing, Editorial, and Other Assistance. Writing assistance was provided by Manju Janardhanan, MD, and Santanu Bhadra, full-time employees of Eli Lilly and Company.

Disclosures. Dr. Giles reported financial relationships with Eli Lilly \& Company, Pfizer, Gilead, Bristol Myers Squibb, and UCB. Dr. Simon reported financial relationships with Abbott, Abraxxis, AcelRx, Affinergy, Agenus, Alpha Rx, Alder, Alimera, Altea, Analgesic Solutions, Antares, Anthera, Array, Asahi, AstraZeneca, Avanir, Bayer, CaloSyn, Cephalon, Cerimon, Daiichi Sankyo, Dara, Dr. Reddy's, DURECT, Eicos Sciences, Eli Lilly and Company, EMD Serono, Eupraxia, Extera, Fidelity, Flexion, Forest, Genco, Genzyme, Gilead, Hisamatsu, Horizon, Idera, Imprimis, Inmedix, Inotek, Jazz, JP Morgan, JRX Biopharm, Kiniksa, Knopp,
Kowa, Leerink Swann, Luxor, Medac, Metabolex, Neos, Nomura, Novartis, NuvoResearch, Omeros, Parexel, Pfizer, PLx Pharma, Pozen, Proprius, pSivida, Purdue, Regeneron, Remedy, Rigel, Roche, Sammuded, Sandoz, Sanofi, Shire, Takeda, Talagen, Teva, TiGenix, Vical, Wyeth, XTL, and Zydus. Dr. Pope reported financial relationships with AbbVie, Actelion, Amgen, Bayer, BMS, Eicos Sciences, Eli Lilly and Company, Emerald Health Pharmaceuticals, Genzyme, Gilead, Janssen, Merck, Novartis, Pfizer, Roche, Sandoz, Sanofi, Seattle Genetics, and UCB. J. Paik, C. Kannowski, A. Quebe, and C. Salinas are employees and stockholders of Eli Lilly and Company. M. Grabner is an employee of HealthCore, Inc., which was under contract with Eli Lilly and Company for the conduct of the study. Dr. Curtis reported financial relationships with AbbVie, Amgen, BMS, Corrona, Eli Lilly and Company, Janssen, Myriad, Pfizer, Regeneron, Roche, and UCB.

Compliance with Ethics Guidelines. Researchers' access to claims data was limited to data stripped of identifiers to ensure confidentiality. HealthCore maintains data use agreements with the covered entities in compliance with the Health Insurance Portability and Accountability Act. Permission was obtained from HealthCore to access the database. An Institutional Review Board did not review the study since only this limited/deidentified data set was accessed.

Data Availability. The datasets generated during and/or analyzed during the current study are not publicly available due to their proprietary nature and the associated restrictions that apply to their availability to external sources. Data may be made available through the corresponding author upon reasonable request and with permission of HealthCore.

Open Access. This article is licensed under a Creative Commons Attribution-NonCommercial 4.0 International License, which permits any non-commercial use, sharing, adaptation, distribution and reproduction in any medium or format, as long as you give appropriate credit to the original author(s) and the source, provide 
a link to the Creative Commons licence, and indicate if changes were made. The images or other third party material in this article are included in the article's Creative Commons licence, unless indicated otherwise in a credit line to the material. If material is not included in the article's Creative Commons licence and your intended use is not permitted by statutory regulation or exceeds the permitted use, you will need to obtain permission directly from the copyright holder. To view a copy of this licence, visit http://creativecommons.org/licenses/by$\mathrm{nc} / 4.0 /$.

\section{REFERENCES}

1. Chiu HY, Huang HL, Li CH, et al. increased risk of chronic kidney disease in rheumatoid arthritis associated with cardiovascular complications-a national population-based cohort study. PLoS One. 2015;10(9):e0136508.

2. Ahn SHJJ. Renal involvement in rheumatic diseases. J Rheum Dis. 2017;24:174-84.

3. Karie S, Gandjbakhch F, Janus N, et al. Kidney disease in RA patients: prevalence and implication on RA-related drugs management: the MATRIX study. Rheumatology (Oxford). 2008;47(3):350-4.

4. Krishnaswami S, Chow V, Boy M, Wang C, Chan G. Pharmacokinetics of tofacitinib, a Janus kinase inhibitor, in patients with impaired renal function and end-stage renal disease. J Clin Pharmacol. 2014;54(1):46-52.

5. Kidney Disease: Improving Global Outcomes (KDIGO) Work Group. KDIGO clinical practice guideline for the evaluation and management of chronic kidney disease. Kidney Int Suppl. 2013;3: $1-150$.

6. Daoussis D, Panoulas VF, Antonopoulos I, et al. Cardiovascular risk factors and not disease activity, severity or therapy associate with renal dysfunction in patients with rheumatoid arthritis. Ann Rheum Dis. 2010;69(3):517-21.
7. Haroon M, Adeeb F, Devlin J, Ogradaigh D, Walker F. A comparative study of renal dysfunction in patients with inflammatory arthropathies: strong association with cardiovascular diseases and not with anti-rheumatic therapies, inflammatory markers or duration of arthritis. Int J Rheum Dis. 2011;14(3):255-60.

8. Couderc M, Tatar Z, Pereira B, et al. Prevalence of renal impairment in patients with rheumatoid arthritis: results from a cross-sectional multicenter study. Arthritis Care Res (Hoboken). 2016;68(5): 638-44.

9. Boers M, Dijkmans BA, Breedveld FC, et al. Subclinical renal dysfunction in rheumatoid arthritis. Arthritis Rheum. 1990;33(1):95-101.

10. Koseki Y, Terai C, Moriguchi M, Uesato M, Kamatani N. A prospective study of renal disease in patients with early rheumatoid arthritis. Ann Rheum Dis. 2001;60(4):327-31.

11. Levey AS, Coresh J, Greene T, et al. Expressing the modification of diet in renal disease study equation for estimating glomerular filtration rate with standardized serum creatinine values. Clin Chem. 2007;53(4):766-72.

12. Pharmacokinetics in patients with impaired renal function. Study design, data analysis, and impact on dosing and labeling [US FDA website] [updated March 2010. 2010. https://www.fda.gov/regulatoryinformation/search-fda-guidance-documents/ pharmacokinetics-patients-impaired-renalfunction-study-design-data-analysis-and-impactdosing-and.

13. Thomas R, Kanso A, Sedor JR. Chronic kidney disease and its complications. Prim Care. 2008;35(2): 329-44, vii.

14. Matsushita K, Mahmoodi BK, Woodward M, et al. Comparison of risk prediction using the CKD-EPI equation and the MDRD study equation for estimated glomerular filtration rate. JAMA. 2012;307(18):1941-51.

15. Rocco MV, Chapman A, Chertow GM, et al. Chronic kidney disease classification in systolic blood pressure intervention trial: comparison using modification of diet in renal disease and CKD-epidemiology collaboration definitions. Am J Nephrol. 2016;44(2):130-40. 